\title{
Social Media Analytics: Impact \& Implications in Healthcare
}

\author{
Sushant Kumar Vishnoi ${ }^{1} \mid$ Ayushi Saini $^{2} \mid$ Dr. Teena Bagga ${ }^{3}$ \\ ${ }^{1}$ Research Scholar, Amity Businss School, Amity University Uttar Pradesh \\ ${ }^{2}$ Student, Amity University Uttar Pradesh \\ 2 Professor, Amity University Uttar Pradesh
}

To Cite this Article

Sushant Kumar Vishnoi, Ayushi Saini and Dr. Teena Bagga, "Social Media Analytics: Impact \& Implications in Healthcare", International Journal for Modern Trends in Science and Technology, Vol. 06, Issue 06, June 2020, pp.:22-28; https://doi.org/10.46501/IJMTST060606

\section{Article Info}

Received on 27-April-2020, Revised on 23-May-2020, Accepted on 23-May-2020, Published on 30-May-2020.

\section{ABSTRACT}

Sharing of ideas, opinions or any information with the help of the medium of virtual networks, online communities and computer-based innovations is known as social media. Blogs, social networking sites like Facebook, WhatsApp, YouTube etc, Microblogging mediums, Photos etc. that run with the help of internet, provides the end-users with swift communication and aids in providing awareness, by influencing large audiences contributes to social media. Healthcare sector is rapidly adapting social media by providing a medium to the patients, physicans and HCP's to discuss and communicate medical information and knowledge outside the vicinity of a hospital or clinic. These days, patients, their relatives, friends or family use the social media to provide knowledge to the world and educate them incase they have similar ailments. There are several blogs and forums related to medical knowledge where users tend to ask their problems to the physicians and get a reply back to their problems. Medical specialists join such online medical forums that helps them to research in a better manner, refer colleagues, increase their network and read health related articles and updates. With every good thing, comes an attached risk which is related to the use of social mediums, where the image of a Healthcare professional could be at stake due to the unprofessional content against them. There are various limitations to the HCP's in case they seek to share patient stories online as it could be a case of breach \& privacy. Nevertheless, this research study highlights the role played by social media in digitally redefining and empowering healthcare sector from the perspective of clinical and patient centric health literacy and health guides.

KEYWORDS: Social Media Analytics, Social Networking Sites, Healthcare, Blogs, Microblogging.

Copyright (C) 2014-2020 International Journal for Modern Trends in Science and Technology

DOI: https://doi.org/10.46501/IJMTST060606

\section{INTRODUCTION}

The healthcare industry helps in providing various facilities and services in regard of the treatment of the patients with extraordinary care, that's curable. The healthcare sector includes several establishments that helps in the dealing of diagnosing the patients and providing treatments of the illness that is diagnosed. These treatments, however are treated by providing facilities privately or publicly.The healthcare industry, after various innovations has been categorized into several sub-sectors. The helathcare sector in India stood at Rs 4 lakh crore (US\$ 61.79 billion) in FY17 and is 
expected to reach Rs $8,60,000$ crore (US\$ 132.84 billion) by FY22. (IBEF, 2019).

Table 1: Indian healthcare schemes with their budget

\begin{tabular}{|l|l|l|}
\hline Year & Yojana & Budget \\
\hline 2005 & $\begin{array}{l}\text { Janani Suraksha } \\
\text { Yojana }\end{array}$ & $\begin{array}{l}\text { Rs 2013 crore } \\
(2017-18)\end{array}$ \\
\hline 2008 & $\begin{array}{l}\text { Rashtriya Swasthya } \\
\text { Bima Yojana }\end{array}$ & $\begin{array}{l}\text { Rs. 2000 crore } \\
(2018-19)\end{array}$ \\
\hline 2017 & $\begin{array}{l}\text { Pradhan Mantri } \\
\text { Matru Vandana } \\
\text { Yojana }\end{array}$ & $\begin{array}{l}\text { Rs 2018-19) } \\
(2000\end{array}$ \\
\hline 2018 & $\begin{array}{l}\text { Pradhan Mantri Jan } \\
\text { Arogya Yojana }\end{array}$ & $\begin{array}{l}\text { Rs. 6400 crores } \\
(2019-20)\end{array}$ \\
\hline
\end{tabular}

Private consultations with HCP's, aimed diagnosis \& treatments, alongwith the facility of mobile applications; all of this has resulted in better patient care and a much better experience for the patient overall. (Jones M. , 2018). As pera research conducted by, (Gartner, 2016), nearly $10 \%$ of the healthcare firms tend to practice some or the other form of prescrptive analysis; morever this percentile has increased from 3\% in 2014 and is expected to rise to $35 \%$ by 2020 . Exceptional conditions like huge investments in predictive analytics, rapid growth of IoT potentials and capabilities that aid in prescriptive analytics are running this growth and helping it to expand the scope of prescriptive models. The Indian healthcare industry is at it's peak of growth and tends to have a very active pace because of the fact that is has a strengthening coverage, facilities and increasing expenditure by public \&private parties (Sarada, 2017). The healthcare sector and it's delivery includes hospitals, nursing homes and diagnostics centres, and pharmaceuticals which constitutes 65 per cent of the overall market.

There are various online platforms, where users create their profiles and interact with each other on these portals/platforms (Vishnoi \& Bagga, 2020). Such websites, which are used for online interactions are called as social networking sites. These platforms allow privacy and give options to the users to accept or reject a new user in their profile. The social networking sites have constantly evolved and improved the user interface for better experience of the users (Bagga, 2012). There is ample number of social networking websites but amongst them, the further section discusses about Facebook, Twitter, LinkedIn, WhatsApp and Instagram.

Health care associations, including clinics, hospitals, pharmaceutical organizations, patient groups, and drug store organizations, are utilizing online platforms for various reasons. Communicating with the network and patients; upgrading hierarchical deceivability; promotion of products and services; giving a channel to the patients to back up resources and instructions; and giving client care and support. Social networking websites have also permitted drug stores to converse with enormous gatherings of clients at the same time, to study various surveys and conduct them, and to empower patients to feel that they are an integral part of the drug store network.

The key challenge for healthcare over social media and other online websites or blogs is often the content that lacks credibility, quality and reliability. Many researchers that study medicine revealed that information related to health on social networking sites (SNS) is not accurate and complete (Bagga, Goyal, \& Bansal, 2016). Moreover, the medical information provided on these SNS is often without any references and are informal in their context. There are several worries in regard to the usage of social networking platforms by HCPs, often point over the probability for adverse consequences resulting from the violation of patient's confidentiality. There's a critical concern regarding the patient's permission in order to connect to them on social media. An $\mathrm{HCP}$ or health care association needs to ensure the patient's permission before posting anything about the patient. Nonetheless, it is eventually up to the HCP, or up to the healthcare firm to opt for seeking the permission of the patient, prior of uploading the pateint's case information over social media.

\section{LITERATURE REVIEW}

As nearly half of the world's population uses social media, be it SNS or blogs or forums etc., the probability of acquiring new customer are very high. As per the reports of eMArketer, social networking sites are playing a vital role in acquiring more and more customers to the existing businesses, as there are approximately 1.7 billion social media users (Ciprian, 2014). Blogs have evolved in their design rather than their convenience, that results the motive of a blog to be an organic human communication (Williams \& Jacobs, 2004). Blogs provide the writers with a freedom of expression in their write-ups, which are spontaneous in nature and may not be compared to any other meida available. (Hull, 2007; Bagga, Sodhi, Shukla, \& Qazi, 2017). (Schmidt, 2007)has provided a list of various types of blogs that 
includes blogs related to politics, corporate field, expert opinions and some may also promote personal experiences and knowledge.Moreover, any subject, thathelps in igniting an interest, among a reasonably sized group of people, has the capibility to become a blog (Kelleher \& Miller, 2006).

One of the recent and trending social phenomena of is Microblogging. In comparison to the other web 2.0 services available, Microblogging, such as Twitter, focuses on the swiftcommunication and immediate reply. The users, with the help of microblogging can upload short messages and express their (Java, Song, \& Finin, 2007; Vishnoi, Bagga, Sharma, \& Wani, 2018). The medical blogs are very important to healthcare professionals and several pharmacists as they gain a lot of important and knowledagble insights from them and along with this, they can sometimes have an opportunity to express their own opinions related to healthcare problems (Jones \& Alony, 2008). Thisbilateral communication format helps in rapid revert and gives a valuable feedback that is not available through conventional media.

The major challenge in the fiels of Digital Marketing is to record the ROI of social marketing. (Leeflang, Freundt, \& Verhoef, 2014; Vishnoi, Tripathi, \& Bagga, 2019)research shows that it is difficult for marketing executives to understand online metrics and turn it into actionable insights, especially when it come to the financial impacts. The rapid expansion in digital media is creating a digital talent gap. (Manyika, 2016) estimate that $440,000-490,000$ of analytically trained people will be needed in the USA in 2018 to analyse customer data, create digital advertisements, develop Web sites, and perform statistical analyses, however, the supply is only 300,000 of these talents. The risks of lack of control increase proportionally with the size and strength of the brand. Consumers can easily become value destroyers instead of value creators for brands. Moreover, creative customers have the tendency to expand their network with other customers having similar hobbies and interests, the market executives can leverage this fact by conducting campaigns online in the online communities and forums. (Elawadi, 2016; Singh, Vishnoi, \& Bagga, 2018).

Visuals have been trending in the recent times and people admire this type of content. This is the reason, why people prefer watching YouTube and have made it the second largest search engine in the world. To the marketers, videos provide a potential return of investment (ROI), because of which, major SNS like Facebook and Instagram push their apps and websites for videos. Instagram's current process offers additional preferences to videos, when they are ranking for the content. In fact, a study by Cisco stated that by $2020,75 \%$ of the mobile traffic would be video. With immense developments, technologies are left behind. Technologies like, Artificial Intelligence (AI) and Augmented Reality (AR) are the trending innovations, which are often confused with virtual reality. Snapchat, a very famous and popular Social media platform has adopted this technology of AR. It has a feature called;'Snapchat Stories', which is now initiated by Facebook and Instagram as well, and these platforms are also reforming it to indulge into competition (Owen, 2019).

\section{Research Methodology:}

This is an exploratory study aimed to understand the role of social media in the healthcare industry. The data was collected from 200 respondents based on age, gender and region, across India with the help of a questionnaire. Secondary research is also used to gather relevant literature and studies specific to the research theme and to allow for fundamental build-up of the research study. Descriptive research is used to understand the impact and implications of social media analytics in healthcare industry. Convenience sampling is used for data collection and analysis of data is done with the help of statistical tools like MS-Excel and SPSS along with the interpretations depicted with the help of Pie-Charts, Bar Graphs and pictorial representation.

\section{Data Analysis:}

Demographic Profile of Respondents

\begin{tabular}{|c|c|c|}
\hline Profile & Frequency & Percentage \\
\hline \multicolumn{3}{|c|}{ Gender } \\
\hline Male & 117 & 58.5 \\
\hline Female & 83 & 41.5 \\
\hline \multicolumn{3}{|c|}{ Age } \\
\hline Below 18 & 4 & 2 \\
\hline Between 19 to 30 & 165 & 82.5 \\
\hline Between 30 to 40 & 21 & 10.5 \\
\hline Between 40 to 50 & 4 & 2 \\
\hline 50 and above & 6 & 3 \\
\hline \multicolumn{3}{|c|}{ India (Region) } \\
\hline North & 106 & 53 \\
\hline East & 22 & 11 \\
\hline South & 28 & 14 \\
\hline West & 44 & 22 \\
\hline TOTAL & 200 & 100 \\
\hline
\end{tabular}


Table 2: Of the total respondents, it was analysed that 83 were females and 117 were males, contributing to $41.5 \% \quad \& \quad 58.5 \%$ respectively.Maximum of the respondents were of the age group: 19-30, comprising of total 165 respondents. Whereas, 30-40 age group comprised of 21 respondents. Age groups of below 18, 40-50 and above 50 had nearly 4-6 respondents each.

Considering the location of the respondents, all of them belong to India. Where, 106 of the total respondents were from Northern region, Western region comprised of 44 respondents. Southern and Eastern regions included 28 and 22 respondents respectively.

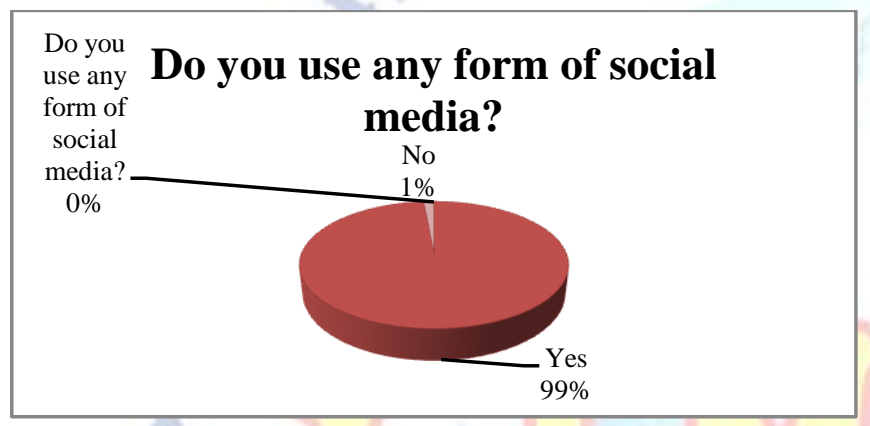

Figure 1: Out of 200 Respondents, 198 use some form of the social media. This reflects that the usage and trend of social media is quite high in today's time.

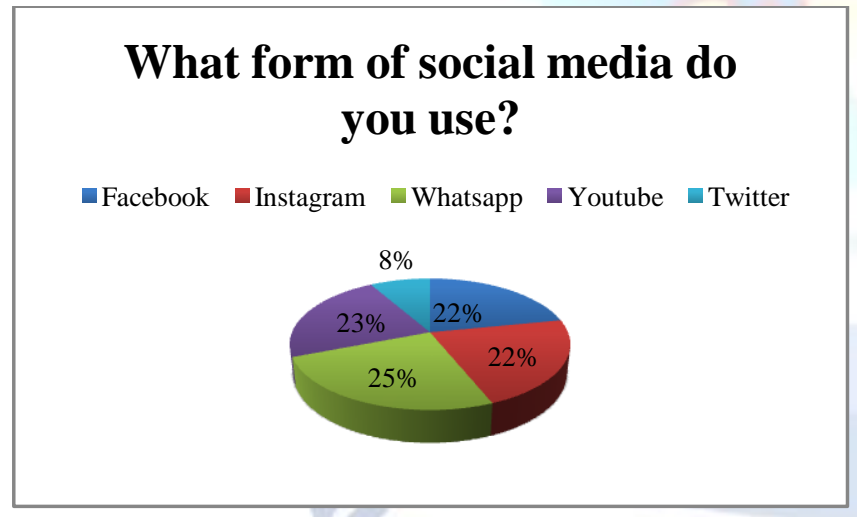

Figure 2: The study revealed that WhatsApp is used the most amongst all the other social networking sites, contributing to almost $25 \%$ of the total respondents. Followed by YouTube, Facebook and Instagram with a total of $23 \%, 22 \% \& 22 \%$ respectively. Out of all the social networking sites, Twitter is least used as per the analysis of the respondents, with a percentile of just $8 \%$ of the respondents.

\section{Do you use social media for healthcare services?}

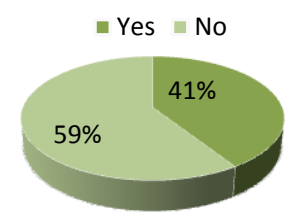

Figure 3: Nearly $60 \%$ of the total respondents use social media for their needs and requirements in healthcare, where as $40 \%$ respondents don't prefer to use it for their healthcare needs. This interprets the growing graph of the social media in healthcare industry.

\section{Which of the following sites/apps do you prefer to use for healthcare, amongst the following?}

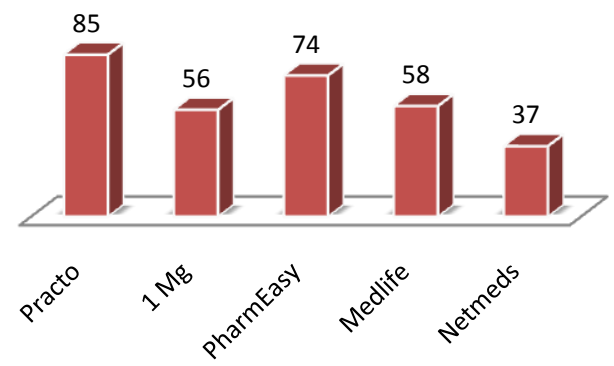

Figure 4:Out of the total respondents, 85 of them use Practo for their healthcare needs. Second most famous site for healthcare as per the responses is PharmEasy with a total of 74 respondents. 58 and 56 respondents use Medlife and $1 \mathrm{Mg}$ sites respectively. Netmeds is not considered much reliable in comparison to the rest of the sites as just $37 / 200$ respondents use it for their Healthcare needs. This interprets that Practo is the most used site for any of the healthcare needs.

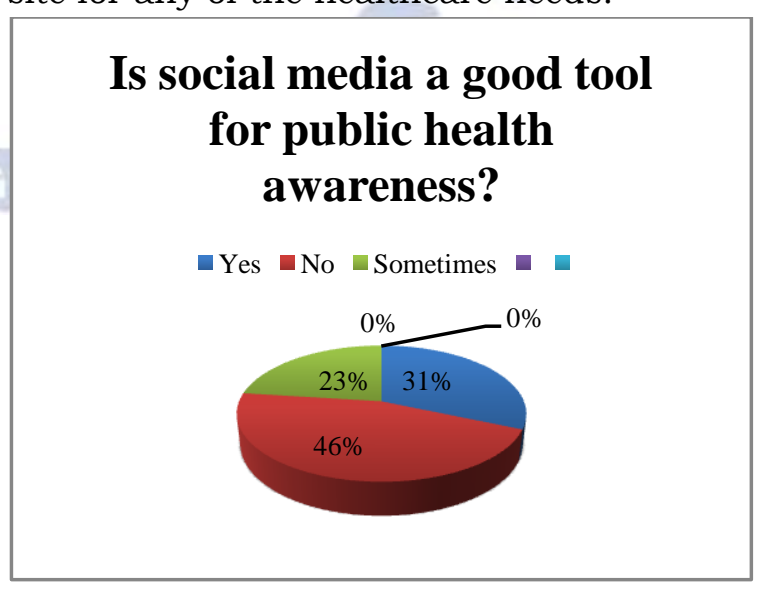


Figure 5: $46 \%$ of the respondents feel that social media is not a good tool for public health awareness. Whereas $31 \%$ of the respondents do feel that social media is a good medium to aware public about healthcare. Out of the total, 23\% respondents feel that it's a good tool for public health awareness sometimes. This interprets that social media has credibility issues in the healthcare sector and needs improvement.

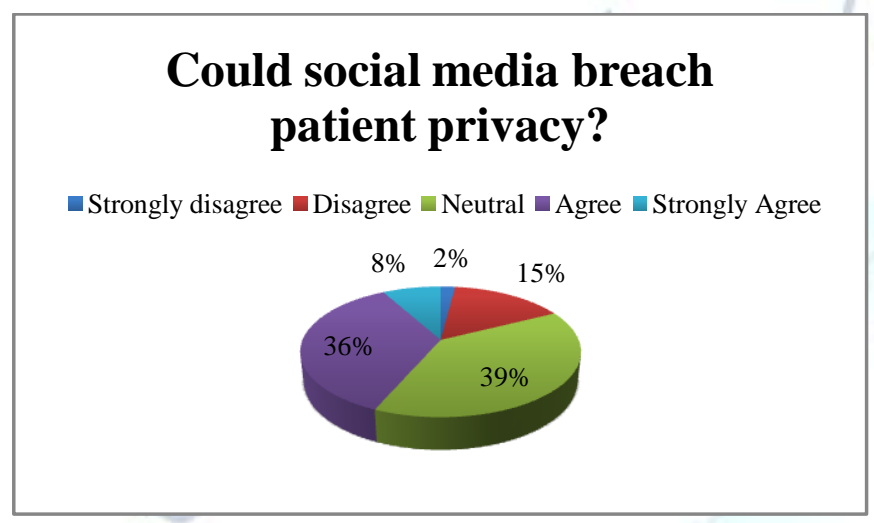

Figure 6: As per the respondents, nearly $36 \%$ agree that social media could breach their privacy. Whereas, $39 \%$ of them feel neutral about the statement. Nearly, $8 \%$ of the respondents strongly agree with the statement. Just a percentile of 15 feels that it can't breach patient privacy. This interprets that social media needs to work on the reliability in order to gain trust of the end user.

\section{Do you trust the information related to healthcare, provided on social media?}

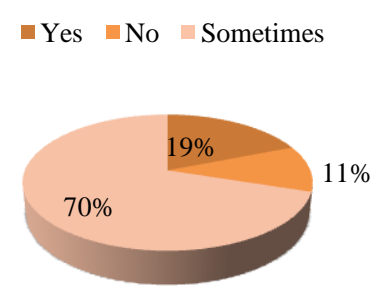

Figure 7:As per the respondents, $70 \%$ only sometimes trust the information provided on social media, as the sources are not credible. Alongside, $19 \%$ trust the information provided on the social media whereas $11 \%$ strictly do not trust any information provided on social media bout healthcare. This shows that social media still needs to hold credible sources in order to make people rely on it for healthcare needs.

\section{Do you contribute on medical forums online?}

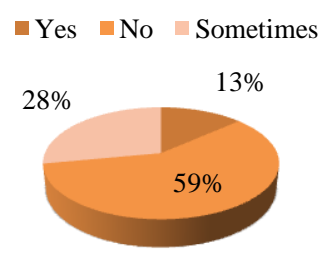

Figure 8: Out of the total respondents, 59\% do not contribute anywhere on the medical forums online. Whereas, $28 \%$ of them do it sometimes and $13 \%$ of the respondents do it on regular basis. This interprets that people might use social media for their own purpose but do not contribute on the online medical forums.

\section{What is your purpose of using social media for healthcare?}
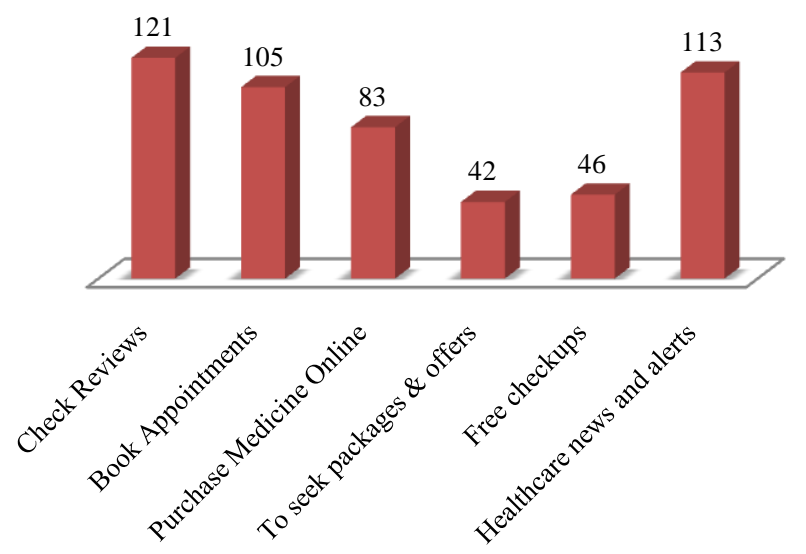

Figure 9: The respondents were given to choose more than one option where at least 133 of them use it for healthcare news and alerts, 121 of them use social media for checking reviews of a hospital or a physician, 105 use it to book appointments and rest use it to purchase medicines online or for free checkups. The least of all the services that's used is to seek packages or offers regarding any healthcare need. 


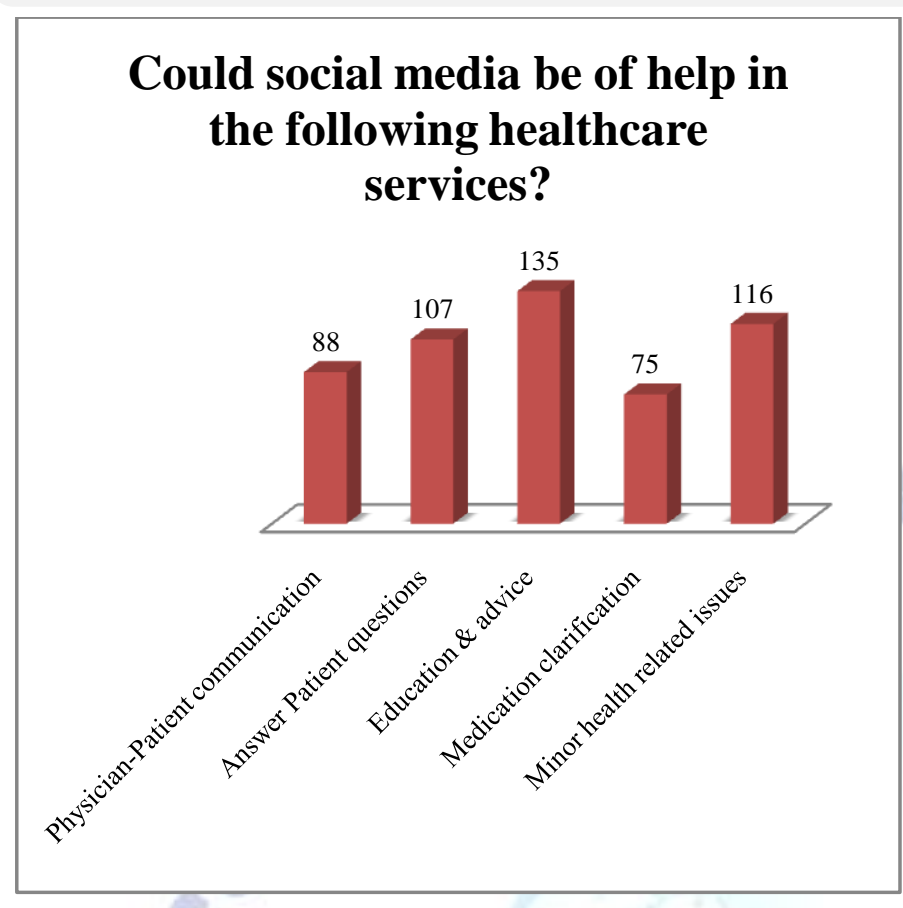

Figure 10:The respondents were given a choice to tick the options where they feel social media can be of help. Maximum of them felt that it's useful to educate general public and advice them for minor health related issues. Nearly 107 of them felt that it's useful for the doctors and physicians to answer their patient's problems online. The least where the respondents felt social media is not of any purpose is clarifying medicine.

\section{Do you recommend your friends \& family to use social media for healthcare services?}

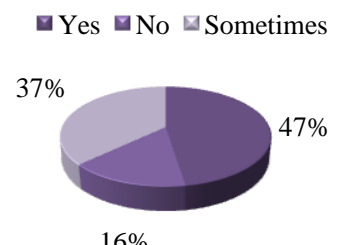

Figure 11:As per the experiences of the respondents, nearly $47 \%$ recommend their families and friends to use social media for healthcare services where as $16 \%$ of the respondents don't recommend it to anyone. $37 \%$ of the respondents sometimes ask their known to use social media for healthcare services. This interprets that word of mouth for social media is quite appreciable.

\section{Conclusion}

Social media has become an important aspect of individual\& organizations. Social media is not a medium left for communication only, it has become a core integral part of advertising, promotion and educating mass media. Gathering large audience is possible with the medium of social media. Healthcare sector has seen immense growth and technology has driven it so well that it is extensively used on social media. The future of social media is immeasurable and will use Augmented reality and Artificial Intelligence to a huge level.

In 2020 and in the future ahead, AI will get developed and will be much better in segmenting data, in order to offer the best content for the people to get indulge into. Eventually, there may come a point where AI technology drives all the manual processes and automate everything. Also, automation and usage of chatbots is hugely beneficial for the online business. Customer response and satisfaction is quite essential for the businesses. If customers are not replied on to what they seek, ask and want, a business is likely to have a threat. Automation and Chatbots are ruling the market past few years and with the introduction of so many human-like technologies, it is quite possible that in the future, over social media, bots close the deal or sell the products at any hour of the day.

\section{Managerial Implications:}

From the above observations, the following implications can be drawn. Primarily, there are many social networking sites available, but the users prefer using WhatsApp, Facebook and YouTube the most. The Healthcare organizations should focus on promoting and advertising their services and facilities on Facebook to reach the maximum number of advertisements. Facebook can use this as an opportunity to engage more customers and bring more traffic to its platform.

Although the users ideally prefer WhatsApp the most, it is not the most convenient platform to advertise products as it is mainly for personal use and is extensively used for Physician-Patient communications. The second most preferred platform, YouTube, can be used to promote extensively as it has a more visual approach, and people are attracted towards visuals and are also capable of posting and engaging more on this platform.

However, the Healthcare sector must understand and should respect the concerns of the users towards their privacy. The patient privacy must not be hampered and should be on top concern. The HCP's must use the social media to communicate 
patient problems and not to interact with them on a personal level as it can makethe patient uncomfortable.

Moreover, the social networking sites should be used for the right purpose, for example, if a physician wants to educate patients, they must create medical blogs and should interact with the users over there. Advertising or promotions should be done over sites like Facebook, YouTube and Instagram. The unfair use should not be done over the social media to degrade or demoralize the image of a HCP, physician or healthcare organization and hence concerns towards that must be fulfilled as well. Also, these platforms should make sure that all the privacy and security measures are well regulated to stop the users from facing any cyber bullying (Cao, Khan, Ali, \& Khan, 2019).

\section{REFERENCES}

[1] Bagga, T. (2012). A study on perception of various social networking sites with special reference to Delhi/NCR. ZENITH International Journal of Business Economics \& Management Research 2, 10, 64-79.

[2] Bagga, T., Goyal, A., \& Bansal, S. (2016). An investigative study of the mobile operating system and handset preference. Indian Journal of Science and Technology, 130-138.

[3] Bagga, T., Sodhi, J., Shukla, B., \& Qazi, M. (2017). Smartphone Security Behaviour of the Indian Smartphone User. Man In India, 97 (24), 333-344.

[4] Cao, X., \& Sun, J. (2018). Exploring the effect of overload on the discontinuous intention of social media users: An SOR perspective. Computers in human behavior, 81, 10-18.

[5] Cao, X., Khan, A. N., Ali, A., \& Khan, N. A. (2019). Consequences of cyberbullying and social overload while using SNSs: A study of users' discontinuous usage behavior in SNSs. Information Systems Frontiers, 1-14.

[6] Ciprian, P. (2014). The Growing Importance of Social Media in Business Marrketing. Quaestus Multidisciplinary Research Journal, 94-98.

[7] Elawadi, I. (2016). Digital Marketing and Social Media: Challenges and Solutions. Journal of Technology, 1-7.

[8] Gartner. (2016). Forecast Snapshot: Prescriptive analytics. United States: Gartner Worldwide.

[9] Hull, D. (2007). Blogging between the lines. American Journalism Review, 62-67.

[10] IBEF. (2019, December 19). Industry (Healthcare). Retrieved December 19, 2019, from India Brand Equity Foundation: www.ibef.org

[11] Java, A., Song, X., \& Finin, T. (2007). Why We Twitter: Understanding Micrblogging Usage and Communi. Web Mining and Social Network Analysis, 56-65.

[12] Jones, M. (2018, December 26). Healthcare. Retrieved December 26, 2018, from Healthcare in America: healthcareinamerica.us

[13] Jones, M., \& Alony, I. (2008). Blogs- The New Source of Data Analysis. Issues in informing Science and Information Technology, 433-445.

[14] Kelleher, T., \& Miller, B. (2006). Organizational Blogs and the Human Voice. Journal of Computer-Mediated Communication, 395-414.
[15] Kim, S.-S., Scott, D., \& Crompton, J. L. (1997). An exploration of the relationships among social psychological involvement, behavioral involvement, commitment, and future intentions in the context of birdwatching. Journal of Leisure Research, 29(3),, 320-341.

[16] Lee, E. (2018). The Antecedents of SNS Fatigue: Influences on Intention to Continuous Usage and Discontinuing Intention. Journal of the HCI Society of Korea, 13(2), 21-29

[17] Lee, E., Lee, K.-Y., Sung, Y., \& Young-A. (2019). DeleteFacebook: Antecedents of Facebook Fatigue. Cyberpsychology, Behavior, and Social Networking, 22(6), 417-422.

[18] Leeflang, P., Freundt, T., \& Verhoef, P. (2014). Challenges and Solutions for marketing in a digital era. European Management Journal, 1-12.

[19] Lo, J. (2019). Exploring the buffer effect of receiving social support on lonely and emotionally unstable social networking users. Computers in Human Behavior, 90, 103-116.

[20] Luqman, A., Cao, X., Ali, A., Masood, A., \& Yu, L. (2017). Empirical investigation of Facebook discontinues usage intentions based on SOR paradigm. Computers in Human Behavior, 70, 544-555.

[21] Luqman, A., Masood, A., \& Ali, A. (2018). An SDT and TPB-based integrated approach to explore the role of autonomous and controlled motivations in "SNS discontinuance intention". Computers in Human Behavior, 85, 298-307.

[22] Manyika, J. (2016). Big Data: The next frontier for innovation, competition and productivity. Innovation in Big Data, 5-8.

[23] Nawaz, M. A., Shah, Z., Nawaz, A., Asmi, F., Hassan, Z., \& Raza, J. (2018). Overload and exhaustion: Classifying SNS discontinuance intentions. . Cogent Psychology, 5(1), 1-18.

[24] Owen, J. (2019, December 16). Social Media Marketing. Retrieved December 16, 2019, from Tech Jackie: techjackie.com

[25] Park, K., \& Koh, J. (2018). Factors Affecting Individuals' Intentions to Discontinue Social Network Services Use. Asia Pacific Journal of Information Systems, 28(1), 19-35.

[26] Sarada, J. (2017). An introduction of Data Analytics in Healthcare industry. ICIAEIT, 169-173.

[27] Schmidt, J. (2007). Blogging Practices: An Analytical Framework. Journal of Computer-Mediated Communication, 1409-1427.

[28] Singh, A., Vishnoi, S. K., \& Bagga, T. (2018). A Study on Customer Preferences towards Travel and Tourism Sector and Their Services. International Journal of Research in Advent Technology, Vol.6, No.12, 3847-3854.

[29] Vishnoi, S. K., \& Bagga, T. (2020). Marketing Intelligence: Antecedents and Consequences. 3rd International Conference On Innovative Computing And Communication(pp. 1-9). New Delhi: Elsevier

[30] Vishnoi, S. K., Bagga, T., Sharma, A., \& Wani, S. N. (2018). Artificial Intelligence enabled marketing solutions : A Review. Indian Journal of Economics \& Business, 167-177.

[31] Vishnoi, S. K., Tripathi, A., \& Bagga, T. (2019). Intelligent Automation, Planning \& Implementation: A Review of Constraints. International Journal on Emerging Technologies, 174-178.

[32] Wenninger, H., Cheung, C. M., \& Krasnova, H. (2019). College-Aged users behavioral strategies to reduce envy on social networking sites: A cross-cultural investigation. Computers in Human Behavior, 97, 10-23.

[33] Williams, J., \& Jacobs, J. (2004). Exploring the use of blogs as learning spaces in the higher education sector. Australasian Journal of Educational Technology, 232-247. 